\title{
Atypical cytomorphology of Gaucher cells is frequently seen in bone marrow smears from untreated patients with Gaucher disease type 1
}

\author{
Alicja Markuszewska-Kuczynska', Monika Klimkowska², Sofie Regenthal'², \\ Agnes Bulanda ${ }^{3}$, Cecilia Kämpe Björkvall ${ }^{4}$, Maciej Machaczka ${ }^{1,5}$
}

${ }^{1}$ Hematology Center Karolinska and Department of Medicine at Huddinge, Karolinska Institutet, Karolinska University Hospital Huddinge, Stockholm, Sweden

${ }^{2}$ Department of Clinical Pathology and Cytology, Karolinska University Hospital Huddinge, Stockholm, Sweden

${ }^{3}$ Basildon and Thurrock University Hospitals, Basildon, Essex, United Kingdom

${ }^{4}$ Department of Medicine, Sunderby Regional Hospital of Norrbotten County, Luleå, Sweden

${ }^{5}$ Medical Faculty, University of Rzeszow, Rzeszow, Poland

\begin{abstract}
Introduction. Gaucher cells (GCs), the lipid-laden storage macrophages, are the pathologic hallmark of Gaucher disease (GD). They are typically $20-100 \mu \mathrm{m}$ in diameter with eccentrically placed nuclei and cytoplasm with characteristic crinkles and striations. A few previous observations have indicated that sometimes GD patients may display morphology of GCs which is different from this classical description. The aim of our study was to explore the morphological polymorphism of GCs in patients with untreated GD type 1 (GD1).

Material and methods. May-Grünwald Giemsa stained bone marrow smears (BM-S) from 6 patients with sporadic GD1 were analysed; each patient sample consisted of two slides where all GCs and non-Gaucher cell macrophages were counted. We have defined for the study purposes and examined the following features of GCs which were considered as atypical: (1) foamy cytoplasm, (2) centrally placed nucleus, (3) cell diameter $>100 \mu \mathrm{m}$, (4) multinuclearity, (5) syncytial morphology, (6) unusually large cytoplasmic projections, and (7) apparent haemophagocytosis. Results. All analysed patients showed 22-40\% GCs with atypical cytomorphology (median 29\%). The median number of atypical features of GCs was 10 per patient (range 6-13). Multinuclearity was the most common atypical feature of GCs, followed by erythrophagocytosis and foamy cytoplasm. There was a strong positive correlation between erythrophagocytosis and foamy cytoplasm in GCs (Spearman's rank correlation coefficient: $0.9)$. Although majority of atypical GCs had one atypical feature, there was a considerable amount of GCs presenting $\geq 2$ atypical features.

Conclusions. Untreated patients with GD1 often show a considerable proportion of GCs with atypical cytomorphology. The knowledge of possible atypical variant forms of GCs can contribute to a quicker and accurate diagnosis of GD, and minimize the risk for misdiagnosis. To the best of our knowledge, this is the first published report on atypical cytomorphology of GCs in untreated patients with GD1. (Folia Histochemica et Cytobiologica 2015, Vol. 53, No. 1, 62-69)
\end{abstract}

Key words: Gaucher disease; Gaucher cells; aspiration biopsy; bone marrow smears; cytomorphology

Correspondence address: Assoc. Prof. M. Machaczka

Hematology Center Karolinska

Karolinska University Hospital Huddinge

Hälsovägen, M54

SE-141 86 Stockholm, Sweden

tel.: +46 858582663 , fax: +4687748725

e-mail: maciej.machaczka@ki.se 


\section{Introduction}

Gaucher disease (GD), although rare, is one of the most common glycolipid storage disorders, caused by an inherited deficiency of the lysosomal enzyme, glucocerebrosidase, arising from autosomal recessive mutations in the GBA1 gene (1q21) [1,2].

Cytomorphologically noticeable lysosomal accumulation of the uncleaved glucocerebroside is restricted, for not completely understood reasons, to one cell type belonging to the monocyte-macrophage series $[3,4]$. These lipid-laden storage macrophages, referred to as 'Gaucher cells', are the pathologic hallmark of GD [5-7]. Gaucher cell (GC) is typically a large cell of $20-100 \mu \mathrm{m}$ diameter with small, eccentrically placed nucleus, has slightly basophilic cytoplasm with characteristic crinkles or striations described as having a 'crumpled or wrinkled tissue paper' appearance (Figure 1A) [2, 5, 6]. Infiltrates of GCs can be found in organs and tissues enriched in cells of the mononuclear phagocyte system, such as spleen, liver and in particular, bone marrow [5-11].

Three clinical types of GD are distinguished according to the absence (type 1) or presence (types 2 and 3 ) of neurological symptoms and the dynamics of developing clinical signs $[1,2,12]$. The most prevalent form of GD is non-neuronopathic GD type 1 (GD1). GD1 is a slowly progressive illness, and clinical picture can vary from severe, lethal cases diagnosed in early childhood to completely asymptomatic patients [13-16]. Currently, GD is treatable and in the European Union there are two treatment options available for patients: (1) enzyme replacement therapy (ERT) with macrophage-targeted recombinant glucocerebrosidase $\left(\right.$ Cerezyme $^{\circledR}$, Genzyme Corporation, Cambridge, MA, USA; VPRIV $^{\circledR}$, Shire HGT, Lexington, MA, USA), and (2) substrate reduction therapy (SRT) with miglustat/N-butyldeoxynojirimycin (Zavesca ${ }^{\circledR}$, Actelion Pharmaceuticals, Allschwil, Switzerland) [17-20].

Only a few previous observations have indicated that sometimes GCs may display cytomorphology which is different from the classical description of GC. These atypical GCs may be of a larger size or may contain a vacuolated, foamy cytoplasm, a centrally placed nucleus, more than one nucleus, cytoplasmic projections, hemosiderin and/or apparent phagocytosis of haematopoietic cells and/or thrombocytes [21-28]. However, so far, there were no published studies examining this issue.

The aim of our study was to explore the morphological polymorphism of GCs present in the bone marrow of patients with GD1.

\section{Material and methods}

Patients and material collection. Between 2002 and 2014, 16 of 35 (46\%) Swedish patients with GD1 were followed at the Karolinska University Hospital in Stockholm. Of these, 6 patients with sporadic GD1 who initially underwent diagnostic bone marrow examination were included in this analysis.

In all patients studied, the diagnosis of GD was confirmed by low glucocerebrosidase activity in peripheral blood leukocytes (Table 1). All patients also demonstrated increased plasma chitotriosidase activity. Both enzymes were assessed by a reference laboratory according to standard practice $[6,19]$. Further, direct DNA sequencing performed at the Academic Medical Centre in Amsterdam, Netherlands, revealed mutations in the $G B A 1$ gene in all cases. The patients' files were reviewed to collect relevant clinical data. All patients provided their informed consent. The basic patient characteristics are summarized in Table 1.

Bone marrow samples were collected under local anaesthesia from an entry site on the posterior iliac crest of patients in the prone position. May-Grünwald Giemsa (MGG) staining of bone marrow smears (BM-S) had previously been performed by laboratory staff according to the

Table 1. Patient characteristics

\begin{tabular}{|l|c|}
\hline Feature $(\boldsymbol{n}=\mathbf{6})$ & Result \\
\hline Age (years) & $21-84$ \\
range & 62 \\
mean & 65 \\
median & \\
\hline Sex & $4(67 \%)$ \\
male & $2(33 \%)$ \\
female & $3(50 \%)$ \\
\hline Splenectomy & \\
\hline Bone disease & $3(50 \%)$ \\
symptomatic & $6(100 \%)$ \\
radiological & \\
\hline Glucocerebrosidase activity in peripheral blood & \\
leukocytes (ref.: $2.1-3.8 \mu$ kat/kg protein) & $0.10-0.59$ \\
range & 0.39 \\
mean & 0.42 \\
median & \\
\hline Chitotriosidase activity in plasma & \\
(ref.: $>40$ nkat/L) & $1322-9743$ \\
range & 3339 \\
mean & 2309 \\
median & \\
\hline GBA1 gene mutations & $1(17 \%)$ \\
c.1226A $>$ G/c.1226A $>$ G & $4(67 \%)$ \\
c.1226A $>$ G/other ${ }^{1}$ & $1(17 \%)$ \\
\hline other/other ${ }^{2}$ & \\
\hline & \\
\hline
\end{tabular}

${ }^{1}$ c. $721 \mathrm{G}>\mathrm{A}(1$ patient); c.1448T $>\mathrm{C}$ ( 2 patients); c. $1448 \mathrm{~T}>\mathrm{C}$, c. $1483 \mathrm{G}>\mathrm{C}$, c. $1497 \mathrm{G}>\mathrm{C}(1$ patient $)$ ${ }^{2} \mathrm{c} .798 \mathrm{C}>\mathrm{G} / \mathrm{c} .1040 \mathrm{~T}>\mathrm{G}$ 


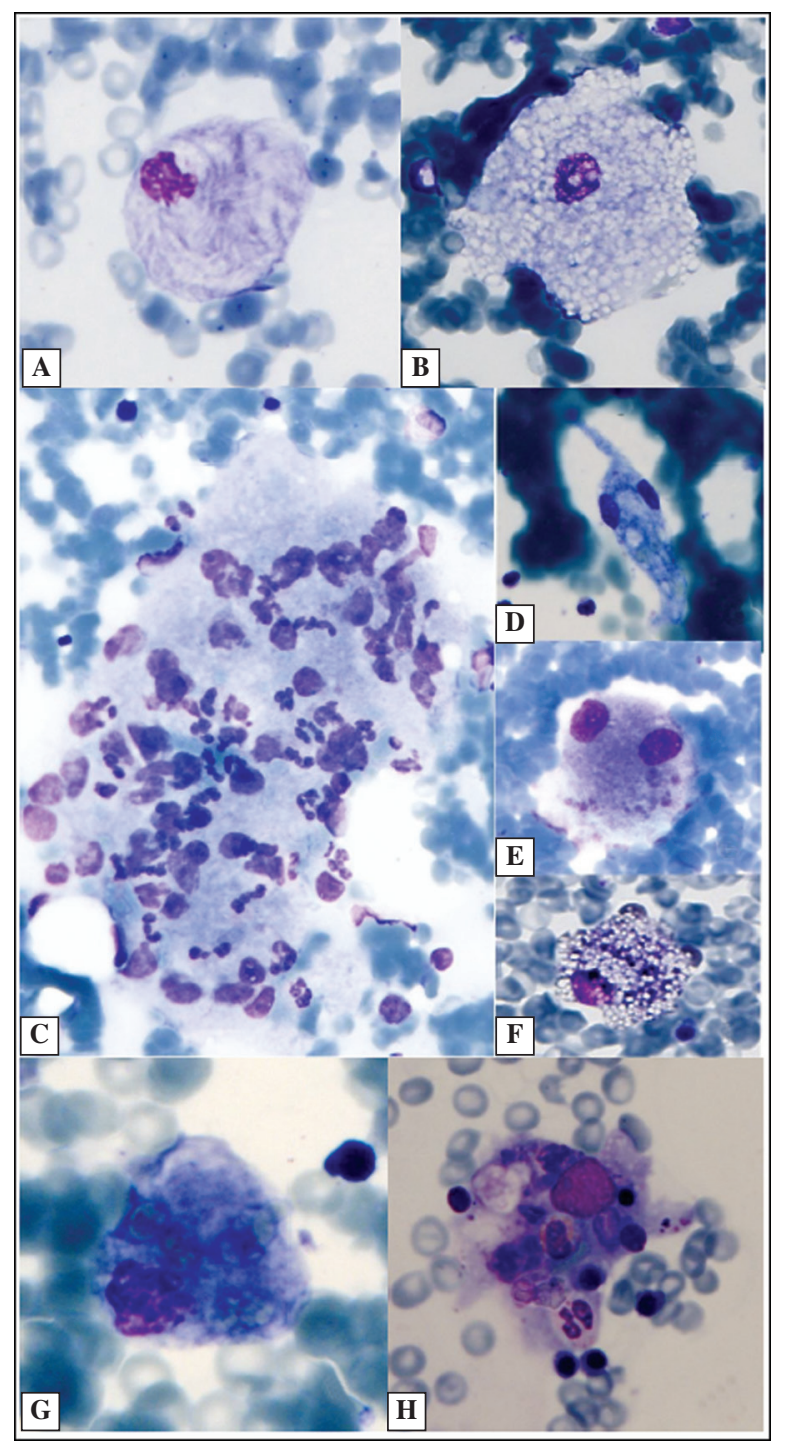

Figure 1. Gaucher cells showing typical (A) and atypical (B-H) morphology. A. Typical Gaucher cell (GC) with fibrillary cytoplasm and an eccentric placed nucleus; B. GC with foamy cytoplasm and almost central nucleus; C. A syncytium of GCs with phagocytosed neutrophilic granulocytes; D. GC with cytoplasmic projections and two nuclei; E. GC with two nuclei and thrombophagocytosis; F. Foamy GC with hemosiderin grains; G. GC with erythrophagocytosis; H. GC with phagocytosis of erythroblasts, neutrophilic granulocytes, an eosinophilic granulocyte and some unidentified nucleated cells. Bone marrow smears, May-Grünwald Giemsa staining

standard procedures of the Centrum for Cell Analysis at the Pathology Department, Karolinska University Hospital Huddinge, and then re-assessed for the study purposes. The study protocol was developed according to the ethical standards of the Declaration of Helsinki and approved by the local ethics committee.

Characteristics of atypical Gaucher cells and non-Gaucher cell macrophages. MGG-stained BM-S were analysed at the $40 \times$ objective of Olympus BX 40 microscope (Olympus, Tokyo, Japan). Each patient sample consisted of two slides in which all GCs and non-GC macrophages were counted (i.e., total cell count).
We have defined for the study purposes and examined the following features of GCs which were considered as atypical: (1) foamy cytoplasm (involving $>10 \%$ of the cytoplasm), (2) a centrally placed nucleus (the shortest distance between the nuclear membrane and the cytoplasmic membrane $>2 / 3$ of the cell radius), (3) GC diameter $>100 \mu \mathrm{m}$, (4) multi-nuclear GCs, (5) unusually large cytoplasmic projections (processes) that are longer then the longest diameter of the cell nucleus and thinner than the cells shortest diameter [21, 22], and (6) apparent haemophagocytosis (Figure 1, B-H). Multi-nuclear GCs larger than $100 \mu \mathrm{m}$ were classified as a (7) syncytium. The phagocytosed cells were categorized as erythrocytes, erythroblasts, lymphocytes, 
Table 2. Number and percentage of counted Gaucher cells and non-Gaucher cell macrophages

\begin{tabular}{|l|c|c|c|c|c|c|}
\hline \multirow{2}{*}{ Pt } & \multirow{2}{*}{ S/A (years) } & \multicolumn{3}{|c|}{ Gaucher cells } & \multirow{2}{*}{ Non-Gaucher cells } & \multirow{2}{*}{$\begin{array}{c}\text { A total number of GCs } \\
\text { and non-GCs }\end{array}$} \\
\cline { 3 - 5 } & & Typical morphology & Atypical morphology & All GCs & & 260 \\
\hline 1 & $\mathrm{M} / 81$ & $155(60 \%)$ & $102(40 \%)$ & $257(99 \%)$ & $3(1 \%)$ & 981 \\
\hline 2 & $\mathrm{M} / 84$ & $620(64 \%)$ & $346(36 \%)$ & $966(98 \%)$ & $15(2 \%)$ & 667 \\
\hline 4 & $\mathrm{~F} / 56$ & $508(77 \%)$ & $155(23 \%)$ & $663(99 \%)$ & $4(1 \%)$ & 134 \\
\hline 5 & $\mathrm{~F} / 21$ & $103(78 \%)$ & $29(22 \%)$ & $132(99 \%)$ & $2(1 \%)$ & 411 \\
\hline 6 & $\mathrm{M} / 65$ & $278(69 \%)$ & $126(31 \%)$ & $404(98 \%)$ & $7(2 \%)$ & 2176 \\
\hline
\end{tabular}

Each patient sample consisted of two bone marrow slides in which all Gaucher cells and non-Gaucher cell macrophages were counted. Abbreviations: Pt — patient; S — sex; A — age; M — male; F — female; GCs — Gaucher cells; non-GCs — non-Gaucher cell macrophages

granulocytes, myelopoietic precursors, thrombocytes and unidentified nuclear cells.

The diameter and radius of the cells were estimated by comparison with an erythrocyte (approx. $7 \mu \mathrm{m}$ ), a reticulocyte $(7-10 \mu \mathrm{m})$ or a band/segmented granulocyte (approx. $14 \mu \mathrm{m})$.

The non-GC macrophages were identified based on the absence of the fibrillary structure of the cytoplasm without being foamy, though they could contain a few vacuoles. The non-GC macrophages could sometimes also be smaller than $20 \mu \mathrm{m}$ in diameter but always bigger than $18 \mu \mathrm{m}$ in diameter.

Digital imaging of BM-S was carried out using a Nikon DX m 1200F digital camera mounted on the Nikon Eclipse E1000 microscope (Nikon, Tokyo, Japan) with a $40 \times$ objective.

Statistical analysis. The non-parametric Spearman's rank correlation coefficient was used to assess how well the relationship between two variables can be described using a monotonic function.

\section{Results}

A total of 12 BM-S from 6 patients with untreated GD1 were evaluated. The numbers and proportions of typical and atypical GCs as well as non-GC macrophages found in the BM-S are showed in Table 2.

The median total number of all GCs (typical and atypical) identified on two BM-S from one patient was 533 (range 132-2159) and the median percentage of GCs with atypical features among all GCs was $29 \%$ (range 22-40\%).

The median total number and percentage of nonGC macrophages identified on two BM-S from one patient was very low as compared to GCs: 3 (range $2-17$ ) and $1 \%$ (range $1-2 \%$ ), respectively.

The repertoire of atypical features of GCs in the BM-S ranged from 6 to 13 per patient (median value: 10 ). The youngest patient (patient \#4, splenectomi- sed) had the lowest proportion of atypical GCs and the smallest repertoire of atypical features followed by the patient \#3 (unsplenectomised). GCs with multinuclearity and GCs presenting with erythrophagocytosis, phagocytosis of erythroblasts, thrombocytes and unidentified nuclear cells, could be found in all patients (Table 3 ).

Foamy cytoplasm has been found in all but one patient (median value: $6 \%$ of atypical GCs; range $0-15 \%)$. There were no foamy GCs in the BM-S from the patient \#4 who was the youngest one in the studied group. Furthermore, the two oldest patients had the highest proportion of foamy GCs (Spearman's rank correlation coefficient: 0.8 ).

GCs with a centrally placed nucleus could be found in $5(83 \%)$ patients (median value: $1 \%$ of atypical GCs; range 0-2\%); all of them had also foamy GCs. The GCs with central nucleus had more often a foamy cytoplasm (16\%) than the GCs with an eccentrically located nucleus $(11 \%)$.

Syncytial morphology of GCs was only found in two patients. Multinuclearity was found in all patients, the proportions ranged from 5-18\% of atypical GCs (median of $12 \%$ ). Multinuclear GCs with a diameter of $>100 \mu \mathrm{m}$ that is GCs with syncytial morphology were found only in the BM-S from patients \#5 and \#6, and they were very few (up to $1 \%$ of all GCs).

Cytoplasmic projections could be found in 5 patients (median value: $0.5 \%$ of atypical GCs; range $0-2 \%$ ).

Erythrophagocytosis could be found in all patients ranging from 5-15\% of atypical GCs (median value: $6 \%)$. Phagocytosis of erythroblasts could also be found in all patients (median value: $1 \%$ of atypical GCs; range 0-2\%). Although lymphophagocytosis could be found in 5 patients, granulophagocytosis in 4 patients, and phagocytosis of myeloid precursors in one patient, the proportions of those GCs were close to $0 \%$. Thrombophagocytosis could be found in all patients ranging from 1-9\% of atypical GCs (median 
Table 3. Number and percentage of Gaucher cells showing particular features of atypical cytomorphology

\begin{tabular}{|c|c|c|c|c|c|c|c|c|c|c|c|c|c|c|c|}
\hline \multirow[t]{3}{*}{$\mathbf{P t}$} & \multirow[t]{3}{*}{$\begin{array}{c}\mathbf{S} / \mathbf{A} \\
(\text { years) }\end{array}$} & \multirow{3}{*}{$\begin{array}{l}\text { Total } \\
\text { number of } \\
\text { atypical } \\
\text { GCs }\end{array}$} & \multicolumn{13}{|c|}{$\begin{array}{l}\text { Number of Gaucher cells showing particular features of atypical morphology } \\
\text { (\% of all the patient's GCs) }\end{array}$} \\
\hline & & & \multirow{2}{*}{$\begin{array}{c}\text { Foamy } \\
\text { CP }\end{array}$} & \multirow{2}{*}{$\begin{array}{l}\text { Central } \\
\text { nucleus }\end{array}$} & \multirow{2}{*}{$\begin{array}{c}\mathbf{D}> \\
100 \mu \mathrm{m}\end{array}$} & \multirow{2}{*}{$\begin{array}{c}\text { Multi- } \\
\text { nuclear }\end{array}$} & \multirow[t]{2}{*}{ Syncyt } & \multirow{2}{*}{$\begin{array}{c}\text { CP } \\
\text { project }\end{array}$} & \multicolumn{7}{|c|}{ Apparent haemophagocytosis of particular cell type } \\
\hline & & & & & & & & & Ery & EryBl & Lym & Gra & Mye & Plt & Uns \\
\hline 1 & $\mathrm{M} / 81$ & 102 & $\begin{array}{c}18 \\
(7 \%)\end{array}$ & $\begin{array}{c}5 \\
(2 \%)\end{array}$ & 0 & $\begin{array}{c}30 \\
(12 \%)\end{array}$ & 0 & $\begin{array}{c}1 \\
(0.4 \%)\end{array}$ & $\begin{array}{c}34 \\
(13 \%)\end{array}$ & $\begin{array}{c}5 \\
(2 \%)\end{array}$ & $\begin{array}{c}1 \\
(0.4 \%)\end{array}$ & $\begin{array}{c}2 \\
(1 \%)\end{array}$ & 0 & $\begin{array}{c}18 \\
(7 \%)\end{array}$ & $\begin{array}{c}5 \\
(2 \%)\end{array}$ \\
\hline 2 & $\mathrm{M} / 84$ & 3 & $\begin{array}{c}146 \\
(15 \%)\end{array}$ & $\begin{array}{c}10 \\
(1 \%)\end{array}$ & 0 & $\begin{array}{c}84 \\
(9 \%)\end{array}$ & 0 & $\begin{array}{c}3 \\
(0.3 \%)\end{array}$ & $\begin{array}{c}146 \\
(15 \%)\end{array}$ & $\begin{array}{c}4 \\
(0.4 \%)\end{array}$ & $\begin{array}{c}1 \\
(0.1 \%)\end{array}$ & $\begin{array}{c}5 \\
(1 \%)\end{array}$ & 0 & $\begin{array}{c}7 \\
(1 \%)\end{array}$ & $\begin{array}{c}7 \\
(1 \%)\end{array}$ \\
\hline 3 & $\mathrm{~F} / 56$ & 155 & $\begin{array}{c}42 \\
(6 \%) \\
\end{array}$ & $\begin{array}{c}14 \\
(2 \%) \\
\end{array}$ & 0 & $\begin{array}{c}33 \\
(5 \%) \\
\end{array}$ & 0 & U & $\begin{array}{c}53 \\
(8 \%) \\
\end{array}$ & $\begin{array}{c}9 \\
(1 \%) \\
\end{array}$ & $\begin{array}{c}1 \\
(0.2 \%)\end{array}$ & 0 & 0 & $\begin{array}{c}16 \\
(2 \%)\end{array}$ & $\begin{array}{c}8 \\
(1 \%) \\
\end{array}$ \\
\hline 4 & $\mathrm{~F} / 21$ & $z$ & 0 & 0 & 0 & $\begin{array}{c}17 \\
(13 \%)\end{array}$ & 0 & $\begin{array}{c}2 \\
(2 \%)\end{array}$ & $\begin{array}{c}7 \\
(5 \%)\end{array}$ & $\begin{array}{c}1 \\
(1 \%)\end{array}$ & 0 & 0 & 0 & $\begin{array}{c}1 \\
(1 \%)\end{array}$ & $\begin{array}{c}4 \\
(3 \%)\end{array}$ \\
\hline 5 & $\mathrm{M} / 65$ & 126 & $\begin{array}{c}23 \\
(6 \%)\end{array}$ & $\begin{array}{c}4 \\
(1 \%)\end{array}$ & $\begin{array}{c}2 \\
(0.5 \%)\end{array}$ & $\begin{array}{c}57 \\
(14 \%)\end{array}$ & $\begin{array}{c}2 \\
(0.5 \%)\end{array}$ & $\begin{array}{c}3 \\
(1 \%)\end{array}$ & $\begin{array}{c}21 \\
(5 \%)\end{array}$ & $\begin{array}{c}5 \\
(1 \%)\end{array}$ & $\begin{array}{c}2 \\
(0.5 \%)\end{array}$ & $\begin{array}{c}2 \\
(0.5 \%)\end{array}$ & 0 & $\begin{array}{c}36 \\
(9 \%) \\
\end{array}$ & $\begin{array}{c}1 \\
(0.2 \%)\end{array}$ \\
\hline 6 & $\mathrm{M} / 66$ & 574 & $\begin{array}{c}45 \\
(2 \%)\end{array}$ & $\begin{array}{c}16 \\
(1 \%)\end{array}$ & $\begin{array}{c}2 \\
(0.1 \%)\end{array}$ & $\begin{array}{c}393 \\
(18 \%)\end{array}$ & $\begin{array}{c}2 \\
(0.1 \%)\end{array}$ & $\begin{array}{c}28 \\
(1 \%)\end{array}$ & $\begin{array}{c}104 \\
(5 \%)\end{array}$ & $\begin{array}{c}12 \\
(1 \%)\end{array}$ & $\begin{array}{c}1 \\
(0.1 \%)\end{array}$ & $\begin{array}{c}9 \\
(0.4 \%)\end{array}$ & $\begin{array}{c}2 \\
(0.1 \%)\end{array}$ & $\begin{array}{c}68 \\
(3 \%)\end{array}$ & $\begin{array}{c}46 \\
(2 \%)\end{array}$ \\
\hline
\end{tabular}

Abbreviations: Pt — patient; S — sex; A— age; M — male; F — female; GCs — Gaucher cells; CP — cytoplasm; D — diameter; Syncyt — syncytial morphology; CP project — cytoplasmic projections; Ery — erythrocytes; EryBl — erythroblasts; Lym — lymphocytes; Gra — granulocytes; Mye - myeloid precursors; Plt — blood platelets; Uns — unspecified nuclear cell. Percentage may exceed 100 due to rounding and/or presenting of $\geq 2$ features by some atypical GCs

Table 4. Number and percentage of counted Gaucher cells showing one, two, three or more atypical features

\begin{tabular}{|l|c|c|c|c|}
\hline Pt & S/A (years) & \multicolumn{3}{|c|}{ Gaucher cells presenting with } \\
\hline & & One atypical feature & Combination of 2 atypical features & Combination of $\geq \mathbf{3}$ atypical features \\
\hline 1 & $\mathrm{M} / 81$ & $85(33 \%)$ & $17(7 \%)$ & 0 \\
\hline 2 & $\mathrm{M} / 84$ & $290(30 \%)$ & $47(5 \%)$ & $9(1 \%)$ \\
\hline 3 & $\mathrm{~F} / 56$ & $139(21 \%)$ & $12(2 \%)$ & $4(1 \%)$ \\
\hline 4 & $\mathrm{~F} / 21$ & $26(20 \%)$ & $3(2 \%)$ & 0 \\
\hline 5 & $\mathrm{M} / 65$ & $100(25 \%)$ & $22(5 \%)$ & $4(1 \%)$ \\
\hline 6 & $\mathrm{M} / 66$ & $463(21 \%)$ & $78(4 \%)$ & $33(2 \%)$ \\
\hline
\end{tabular}

Abbreviations: $\mathrm{Pt}$ - patient; $\mathrm{S}$ - sex; $\mathrm{A}$ - age; $\mathrm{M}$ - male; F — female

$2.5 \%)$, and phagocytosis of unidentified nuclear cells could be found in all patients ( $0-3 \%$ of atypical GCs, median value $1.5 \%$ ).

Although most atypical GCs only had one atypical feature, there was a considerable amount of the GCs presenting two or even more atypical features (Table 4). In total, there were 35 different combinations of 2 atypical features and 55 combinations of $\geq 3$ atypical features. The most common combination of 2 atypical features was multinuclearity and erythrophagocytosis followed by foamy cytoplasm and erythrophagocytosis. The most common combination of $\geq 3$ atypical features was foamy cytoplasm, multinuclearity and erythrophagocytosis followed by multinuclearity, erythrophagocytosis and thrombophagocytosis.

\section{Discussion}

Gaucher disease is well known for its striking phenotypic diversity, which can complicate a timely diagnosis. Since GD is rare and its symptoms can be caused by many other conditions, it is not likely to be suspected in a patient not belonging to the more affected populations such as Ashkenazi Jews or the population of Norrbotten (the northernmost Swedish region) [5-6, $10,12,19-31]$.

Historically, diagnosis of GD was usually based on morphological examination of the affected organ (e.g., bone marrow, spleen, liver) [6, 8, 29]. Until 1966, when pseudo-Gaucher cells were described for the first time in chronic myeloid leukaemia, it was believed that the 
presence of GCs in bone marrow was pathognomonic of GD [32]. It must be stressed that currently the golden standard for definitive diagnostics of GD requires confirmation of reduced enzymatic activity of glucocerebrosidase in leukocytes, cultured fibroblasts, or amniocytes obtained during prenatal diagnosis $[1,2]$. Enzymatic assays should therefore always be applied in suspected cases. Measurement of glucocerebrosidase is supplemented by $G B A 1$ mutation analysis [33].

In a general population, in patients without any previously known GD-affected family member, frequent symptoms of GD, such as thrombocytopenia or splenomegaly, often lead to haematological work-up with aspiration biopsy of bone marrow for the cytological assessment of BM-S $[2,6,7,10]$. This can disclose the presence of GCs and lead to the final diagnosis $[2,6]$.

The results of our recently published study showed that aspiration biopsy of bone marrow may provide only a very few GCs for assessment (median: 4 GCs; range 1-18) [31]. Therefore knowledge about unusual, atypical morphology of GCs could be crucial in giving a first clue towards GD diagnosis in some patients.

In the present study, all analysed patients had multinucleated GCs and multinuclearity was the most common atypical feature of GCs. However, there was variability in the proportions of multinuclear GCs between the patients. There are only few previous studies in which multinuclear GCs have been noted $[5,21,26]$, and these observations have never lead to any systematic research on this issue.

Multinucleated giant cells have been observed intermixed with typical GCs in an ultrastructural study by Takahashi and Naito [34]. Syncytial multinuclear giant cells with striated cytoplasm from a GD1 patient have only been described by Ziyeh and Harzer, who suggested that these cells might be osteoclasts which are specialized multinucleated macrophages [25].

Although majority of stored glucocerebroside in GCs is of erythrocyte origin, apparent erythrophagocytosis by GCs in bone marrow has been infrequently reported [5, 22, 26, 28, 35]. The erythrocytes of untreated GD patients have been found by Bratosin et al. to have an altered morphology and reduced viability which may promote erythrophagocytosis [36]. According to them, the alterations in erythrocyte morphology and viability disappeared after 9 months of ERT. We found erythrophagocytosis in BM-S from all patients and it was the second most common atypical feature of GCs. Of note, there was a strong positive correlation between erythrophagocytosis and the presence of foamy cytoplasm in GCs (Spearman's rank correlation coefficient: 0.9 ).

Atypical macrophages of soap bubble or foamy appearance are usual findings in the bone marrow of patients with Niemann-Pick disease [37, 38]. William Bloom in 1925 provided probably the earliest description and microscopic pictures of foamy transformed macrophages in Niemann-Pick disease [39]. However, some other diseases and conditions including Wolman disease, Tangier disease, hypercho-lesterolaemia, hyperchylomicronaemia, adult cholesteryl ester storage disease (CESD), hyperuricaemia, or long-term total parenteral nutrition may also lead to the formation of atypical foamy macrophages [25, 40-42].

Foamy transformed GCs were first reported by Elleder in 1992, in the autopsy report concerning two patients, one with GD type 2 and one with GD type 1 [24]. The author proposed that foamy transformation of GCs could depend on an accentuation of lipid storage, but also on an abnormal storage pattern triggered by external factors (e.g. infection, ischaemia). In 2009, Hůlková et al. published an autopsy case of a 59 year old woman diagnosed with GD1 which was treated with ERT [11]. The authors found foamy or vacuolated GCs in the bone marrow which were located closely to the adipose tissue. Ultrastructural examinations of these foamy GCs revealed lipid droplets in the cytosol, separated from the lysosomal compartments [11]. Two years later, in 2011 our group reported for the first time foamy GCs in the living individual [28]. This latter finding has led us to conduct the present study to investigate polymorphism of GCs in untreated patients with GD1.

Foamy cytoplasm was the third most common atypical feature in the GCs in our study. It is not excluded that there might be a positive correlation between age and proportion of foamy GCs; however, a larger number of patients should be assessed before drawing any final conclusions.

Only a very small proportion of GCs in each of our GD1 patients had a centrally located nucleus and there was no significant variation between the patients considering GCs with central nucleus.

Gaucher cells with cytoplasmic projections have previously been described in two electron-microscopic studies. Pennelli et al. reported a 'small pseudopodia' or 'ridge-like projections similar to microvilli' [22]. In a study by DeMarsh and Kautz long finger-like projections were occasionally encountered [21]. In the present study, GCs with cytoplasmic projections were present in all but one GD1 patient. However, the proportions of GCs with cytoplasmic projections were always very small.

We conclude that untreated patients with GD1 often show a reasonable proportion of GCs with atypical cytomorphology. Initial symptoms of sporadic GD1 often lead to haematological diagnostics, 
including bone marrow examination. Therefore, knowledge of possible atypical variant forms of GCs in BM-S can contribute to a quicker and accurate diagnosis of GD, and minimize the risk for misdiagnosis. To the best of our knowledge, this is the first published report on atypical cytomorphology of GCs in untreated patients with GD1.

\section{Acknowledgements}

This work was supported by grant provided by the Stockholm County Council (ALF project).

\section{References}

1. Zimran A. How I treat Gaucher disease. Blood. 2011;118:1463-1471. doi: 10.1182/blood-2011-04-308890.

2. Machaczka M. What hematologist needs to know about Gaucher disease. Acta Haematol Pol. 2013;44:301-306. doi: 10.1016/j.achaem.2013.07.019.

3. Elleder M. Glucosylceramide transfer from lysosomes - the missing link in molecular pathology of glucosylceramide deficiency: a hypothesis based on existing data. J Inherit Metab Dis. 2006;29:707-715. doi: 10.1007/s10545-006-0411-z.

4. Boven LA, van Meurs A, Boot RG et al. Gaucher cells demonstrate a distinct macrophage phenotype and resemble alternatively activated macrophages. Am J Clin Pathol. 2004;122:359-369. doi: 10.1309/BG5VA8JRDQH1M7HN.

5. Parkin JL, Brunning RD. Pathology of the Gaucher cell. Prog Clin Biol Res. 1982;95:151-175. PMID: 7122633.

6. Machaczka M, Klimkowska M, Hägglund H. Effort bruising disclosing Gaucher disease in a 55-year-old non-Jewish woman. J Inherit Metab Dis. 2009;32:758-761. doi: 10.1007/ /s10545-009-1217-6.

7. Sokołowska B, Skomra D, Czartoryska B et al. Gaucher disease diagnosed after bone marrow trephine biopsy - a report of two cases. Folia Histochem Cytobiol. 2011;49:352-356. doi: 10.5603/FHC.2011.0048.

8. Papla B, Machaczka M, Skotnicki AB. Is it possible to identify siblings by studying bone marrow under a microscope? Two unusual cases of Gaucher disease. Pol J Pathol. 2002;53:87-90. PMID: 12140872.

9. Rudzki Z, Okoń K, Machaczka M et al. Enzyme replacement therapy reduces Gaucher cell burden but may accelerate osteopenia in patients with type I disease - a histological study. Eur J Haematol. 2003;70:273-281. doi: 10.1034/ /j.1600-0609.2003.00047.x.

10. Sokołowska B, Skomra D, Czartoryska B et al. Gaucher disease - one of the possible causes of splenomegaly — case report. Pol Arch Med Wewn. 2004;112:1107-1112. PMID: 15727093.

11. Hůlková $\mathrm{H}$, Ledvinová J, Poupetová H et al. Autopsy case of Gaucher disease type I in a patient on enzyme replacement therapy. Comments on the dynamics of persistent storage process. J Inherit Metab Dis. 2009;32:551-559. doi: 10.1007/ /s10545-009-1178-9.

12. Machaczka M, Kämpe Björkvall C, Wieremiejczyk J et al. Impact of imiglucerase supply shortage on clinical and laboratory parameters in Norrbottnian patients with Gaucher disease type 3. Arch Immunol Ther Exp (Warsz). 2015;63:65-71. doi: 10.1007/s00005-014-0308-8.

13. Lachmann RH, Grant IR, Halsall D, Cox TM. Twin pairs showing discordance of phenotype in adult Gaucher's disease. Q J Med. 2004;97:199-204. doi: 10.1093/qjmed/hch036.
14. Amato D, Stachiw T, Clarke JTR, Rivard GE. Gaucher disease: variability in phenotype among siblings. J Inherit Metab Dis. 2004;27:659-669. PMID: 15669682.

15. Elstein D, Gellman A, Altarescu G et al. Disease severity in sibling pairs with type 1 Gaucher disease. J Inherit Metab Dis. 2010;33:79-83. doi: 10.1007/s10545-009-9024-7.

16. Machaczka M, Klimkowska M. Novel heterozygous c. $798 \mathrm{C}>\mathrm{G}$ and c. $1040 \mathrm{~T}>\mathrm{G}$ mutations in the GBA1 gene are associated with a severe phenotype of Gaucher disease type 1. Ann Hematol. 2014;93:1787-1789. doi: 10.1007/s00277-014-2036-x.

17. Hollak C, vom Dahl S, Aerts JM et al. Force majeure: therapeutic measures in response to restricted supply of imiglucerase (Cerezyme) for patients with Gaucher disease. Blood Cells Mol Dis. 2010;44:41-47. doi: 10.1016/j.bcmd.2009.09.006.

18. Hughes DA, Al-Sayed M, Belmatoug N et al. Early access experience with VPRIV ${ }^{\circledR}$ : recommendations for 'core data' collection. Blood Cells Mol Dis. 2011;47:140-142. doi: 10.1016/j.bcmd.2010.10.015.

19. Machaczka M, Hast R, Dahlman I et al. Substrate reduction therapy with miglustat for type 1 Gaucher disease: a retrospective analysis from a single institution. Ups J Med Sci. 2012;117:28-34. doi: 10.3109/03009734.2011.641609.

20. Machaczka M, Klimkowska M, Hägglund H. Unexpected cure from cutaneous leukocytoclastic vasculitis in a patient treated with N-butyldeoxynojirimycin (miglustat) for Gaucher disease. Adv Med Sci. 2012;57:169-173. doi: 10.2478/ /v10039-012-0021-y.

21. DeMarsh QB, Kautz J. The submicroscopic morphology of Gaucher cells. Blood. 1957;12:324-335. PMID: 13412761.

22. Pennelli N, Scaravilli F, Zacchello F. The morphogenesis of Gaucher cells investigated by electron microscopy. Blood. 1969;34:331-347. PMID: 5804023.

23. Lorber M. Adult-type Gaucher's disease: a secondary disorder of iron metabolism. Mt Sinai J Med. 1970;37:404-417. PMID: 4194895.

24. Elleder M. Foamy transformed Gaucher cells. Zentralbl Pathol. 1992;138:47-50. PMID: 1596484.

25. Ziyeh S, Harzer K. Bone marrow cytological storage phenomena in lipidoses. Eur J Pediatr. 1994;153:224-233. PMID: 8194551.

26. Bitton A, Etzell J, Grenert JP, Wang E. Erythrophagocytosis in Gaucher cells. Arch Pathol Lab Med. 2004;128:1191-1192. PMID: 15387692.

27. Sharpe LR, Ancliff P, Amrolia P et al. Type II Gaucher disease manifesting as haemophagocytic lymphohistiocytosis. J Inherit Metab Dis. 2009;32(Suppl 1):S107-S110. doi: 10.1007/ /s10545-009-1091-2.

28. Machaczka M, Klimkowska M, Regenthal S, Hägglund $\mathrm{H}$. Gaucher disease with foamy transformed macrophages and erythrophagocytic activity. J Inherit Metab Dis. 2011;34:233-235. doi: 10.1007/s10545-010-9241-0.

29. Mistry PK, Cappellini MD, Lukina E et al. A reappraisal of Gaucher disease - diagnosis and disease management algorithms. Am J Hematol. 2011;86:110-115. doi: 10.1002/ /ajh.21888.

30. Mistry PK, Sadan S, Yang R et al. Consequences of diagnostic delays in type 1 Gaucher disease: the need for greater awareness among hematologists-oncologists and an opportunity for early diagnosis and intervention. Am J Hematol. 2007;82:697-701. doi: 10.1002/ajh.20908.

31. Machaczka M, Markuszewska-Kuczyńska A, Regenthal S et al. Clinical utility of different bone marrow examination methods in the diagnosis of adults with sporadic Gaucher disease type 1. Pol Arch Med Wew. 2014;124:587-592. PMID: 25188399 
32. Albrecht M. 'Gaucher cells' in chronic myeloic leukemia. Blut. 1966;13:169-179. PMID: 5219514.

33. Hruska KS, LaMarca ME, Scott CR, Sidransky E. Gaucher disease: mutation and polymorphism spectrum in the glucocerebrosidase gene (GBA). Hum Mutat. 2008;29:567-583. doi: 10.1002/humu.20676.

34. Takahashi K, Naito M. Lipid storage disease: Part II. Ultrastructural pathology of lipid storage cells in sphingolipidoses. Acta Pathol Jpn. 1985;35:385-408. PMID: 2992227.

35. Lee RE, Balcerzak SP, Westerman MP. Gaucher's disease. A morphologic study and measurements of iron metabolism. Am J Med. 1967;42:891-898. PMID: 6067457.

36. Bratosin D, Tissier JP, Lapillonne $\mathrm{H}$ et al. A cytometric study of the red blood cells in Gaucher disease reveals their abnormal shape that may be involved in increased erythrophagocytosis. Cytometry B Clin Cytom. 2011;80:28-37. doi: 10.1002/cyto.b.20539.

37. Da Silva V, Vassella F, Bischoff A et al. Niemann-Pick's disease. Clinical, biochemical and ultrastructural findings in a case of the infantile form.J Neurol. 1975;211:61-68. PMID: 56432.
38. Lossos A, Schlesinger I, Okon E et al. Adult-onset Niemann-Pick type C disease. Clinical, biochemical, and genetic study. Arch Neurol. 1997;54:1536-1541. doi: 10.1001/archneur.1997.00550240084016.

39. Bloom W. Splenomegaly (type Gaucher) and lipoid-histiocytosis (type Niemann).AmJ Pathol.1925;1:595-626. PMID: 19969674.

40. Brunning RD. Morphologic alterations in nucleated blood and marrow cells in genetic disorders. Hum Pathol. 1970;1:99-124. doi: 10.1016/S0046-8177(70)80006-5.

41. Nam MH, Grande JP, Li CY et al. Familiar hypercholesterolemia with unusual foamy histiocytes. Report of a case with myelophthisic anemia and xanthoma of the maxillary sinus. Am J Clin Pathol. 1988;89:556-561. PMID: 3354509.

42. vom Dahl S, Harzer K, Rolfs A et al. Hepatosplenomegalic lipidosis: what unless Gaucher? Adult cholesteryl ester storage disease (CESD) with anemia, mesenteric lipodystrophy, increased plasma chitotriosidase activity and a homozygous lysosomal acid lipase-1 exon 8 splice junction mutation. J Hepatol. 1999;31:741-746. doi: 10.1016/S0168-8278(99) 80356-0.

Submitted: 3 November, 2014 Accepted after reviews: 27 February, 2015 Available as AoP: 2 March, 2015 